the plates were covered with Dulbecco phosphate-buffered saline (for direct, 19S producing plaques), or with species specific anti- $\gamma$-globulin antiserum (for indirect, $7 \mathrm{~S}$ produc. ing plaques) ${ }^{19,20}$. After an additional $90 \mathrm{~min}$ incubation, the plates were rinsed and covered with $1 \mathrm{ml}$. of reconstituted, lyophilized guinea-pig complement (Difco) diluted 1: 10 in Dulbecco phosphate-buffered saline. Haemolytic plaques developed during $2 \mathrm{~h}$ of incubation with comple. ment at $37^{\circ} \mathrm{C}$, and were counted without magnification in direct light by two individuals.

Table 2. APPEARANCE OF ANTI-DNP FORMING CELLS IN MICE FOLLOWING PRIMARY INJECTION OF DNP-RABBIT SERUM ALBUMIN*

\begin{tabular}{|c|c|c|}
\hline \multirow[b]{2}{*}{ Day } & \multicolumn{2}{|c|}{$\mathrm{PFC}_{/} / 0^{7}$ spleen cells $\dagger$} \\
\hline & Direct & Indirect \\
\hline 0 & 3 & 3 \\
\hline 3 & 14 & 3 \\
\hline 7 & 700 & 420 \\
\hline 11 & 161 & 462 \\
\hline
\end{tabular}

* Balb/c mice immunized by intraperitoneal injection of $0.4 \mathrm{mg}$ DNP rabbit serum albumin in $0.2 \mathrm{ml}$. of complete Freund's adjuvant.

$\dagger$ Average of three animas.

$\ddagger$ Developed with goat anti-mouse IgG (Hyland Lab. lot GP 7-66) diluted $1: 50$

This technique was applied to the assay of cells forming antibodies against two different haptens and one protein in mice, rabbits and guinea-pigs. The results (Tables 2 and 3) show rapid increase of "direct" PFC following the third day after immunization and an increase in "indirect" PFC occurring later, similar to those reported by others ${ }^{3-9}$. They also demonstrate that by this technique a very low background is observed and PFC of hapten (DNP) or carrier (BSA) specificity can be determined simultaneously (Table 3). The plaques detected with DNP-FabRBC were completely inhibited by DNP-amino caproate $\left(10^{-5} \mathrm{M}\right)$ and those detected with BSA-Fab-RBC were inhibited by BSA $\left(5 \times 10^{-7} \mathrm{M}\right)$. In the case of rabbit spleen cells it is especially important to have highly specific anti-Fe antiserum for the elucidation of indirect PFC, otherwise non-specific lysis of the Fab coated RBC will occur. Similarly it is also not advisable to use IgG as a carrier or immunogen, for a cross-reaction of anti-IgG and the rabbit Fab used to coat the cells might confuse the results (see Table 3 ).

Table 3. ANTIBODY FORMNG CELLS IN RABBIT SPLEEN AT DIFFERENT STAGES

\begin{tabular}{lcccc} 
Immunogen & Day & $\begin{array}{c}\text { Erythrocytes } \\
\text { coated with }\end{array}$ & $\begin{array}{c}\text { PFC/107 } \\
\text { Direct }\end{array}$ & $\begin{array}{c}\text { spleen cells } \\
\text { Indirect } \dagger\end{array}$ \\
DNP-BSA & 5 & Fab & 20 & 25 \\
& & DNP-Fab & 70 & 30 \\
DNP-BSA & \multirow{2}{*}{ Hyperimmune } & BSA-Fab & 80 & 40 \\
& & Fab & 20 & 30 \\
PEN-bovine IgG & \multirow{2}{*}{13} & BSA-Fab & 40 & 13,000 \\
& & Fab & 37 & 1,480 \\
& & PEN-Fab & 34 & 98
\end{tabular}

* Immunization was by multiple intradermal injections of $2 \mathrm{mg}$ immunogen in complete Freund's adjuvant.

$\dagger$ Developed with goat anti-rabbit-Fc previously adsorbed on rabbit-Fab'Sepharose' column.

Our technique has the following advantages: a series of modified anti-RBC-Fab preparations can be prepared and used as reagents for the assay of PFC with specificity towards the attached ligand. These reagents can be titrated, stored and subsequently used many times with high reproducibility for the coating of erythrocytes. The assay is applicable to both small and large molecules and can measure PFC towards either hapten or carrier in the same system, although the methods and optimal conditions for attachment of the required moiety should be investigated in each case. The attachment of haptens seems quite straightforward in many cases and the effect of hapten density on plaque formation can be studied by varying the number of ligands on the Fab or the number of modified Fab per RBC. The binding of proteins presents more difficulty and the use of bifunctional reagents other than glutaraldehyde is now under investigation in order to improve the assay for protein antigens. The coating of the RBC by the modified Fab is fast and simple and does not change the stability of the RBC. The background $\mathrm{PFC}$ is very low and the assay of different systems can be compared simultaneously, for all of them have the anti. RBC-Fab as a common denominator.

P. S. is a postdoctoral fellow of the American Cancer Society and A. S., on leave of absence from the Institute of Pathological Anatomy, Bucharest, is supported by a fellowship from the World Health Organization. One of us (D. G.) thanks Dr A. Munro and Mr M. Taussig of Cambridge University for diseussion.

\section{P. Stratusbauch}

A. Sulica

D. GIvor

Department of Chemical Immunology,

The Weizmann Institute of Science,

Rehovot.

Received January 14, 1970.

'Jerne, N. K., and Nordin, A. A., Science, 140, 405 (1963).

2 Merchant, B., and Hraba, T., Science, 149, 200 (1966).

${ }^{s}$ Gershon, A., Bauminger, S., Sela, M., and Feldman, M., J. Exp. Med., 128, 223 (1968).

- Kishimoto, S., Tsuyguchi, I., and Yamamura, Y., Intern. Arch. Allergy, 34,

- Yamada, H., and Yamada, A., J. Immunol., 103, 357 (1969).

5 Havas, H. F., and Hraba, T., J. Immunol., 108, 349 (1969).

' Hraba, T., and Merchant, B., J. Immunol., 102, 229 (1969).

${ }^{3}$ Barth, R., and Merchant, B., Proc. Soc. Exp. Biol. Med., 125, 307 (1967).

Golub, E. S., Mishell, R., Weigle, W. O., and Dutton, R. W., J. Immunol. 100, 133 (1968).

${ }^{10}$ Coombs, R. R. A., Mynor, L. S., and Weber, G., Brit. J. Exp. Pathol., 31, $640(1950)$

"Sulica, A., Ghyka, G., and Ghetie, V., Rev. Rcum. Biochim., 5, 145 (1968).

${ }^{12}$ Porter, R. R., Biochem. J., 73, 119 (1959).

Eisen, H. N., in Methods in Medical Research (edit. by Eisen, H. N.), 10, 94 (Year Book Medical Publishers, Chicago, 1964).

${ }^{2}$ Harinchi, Y., and Shibata, K., Intern. Arch. Allergy, 28, 306 (1965).

${ }^{15}$ Quiocho, F. A., and Richards, F. M., Proc. US Nat. Acad. Sci., 52, 833 (1964)

16 Dulbecco, R., and Vogt, M., J. Exp. Med., 99, 167 (1954).

${ }^{17}$ Dulbecco, R., and Freeman, G., Virology, 8, 396 (1959).

1s Hanks, J. H., and Wallace, R. C., Proc. Soc. Exp. Biol. Med., 71, 196 (1949).

${ }^{19}$ Sterzl, J., and Riha, I., Nature, 208, 858 (1965).

${ }^{20}$ Dresser, D. W., and Wortis, H. H., Nature, 208, 859 (1965).

\section{Application of Electron Probe Microanalysis and Electron Microscopy to the Transfer of Antigenic Material}

WE have studied the effect of rarious antilymphocyte sera on lymphocytes, using the Stereoscan electron microscope $e^{1}$, and more recently we described the formation of long intercellular processes between macrophages and lymphocytes in certain conditions ${ }^{2}$. Process formation was particularly marked if macrophages from rats sensit. ized to tuberculin were incubated first with PPD and then with either normal lymph node cells or lymph node cells from rats sensitized to tuberculin (Fig. 1). In the former case, many macrophages were seen to be closely surrounded by clusters of lymphocytes.

We describe here an attempt to produce evidence for the hypothesis that transfer of antigenic material from cell to cell occurs along thesc intercellular processes. The antigenic protein used was PPD. It was labelled with iodine and subsequent cell preparations scanned for iodine distribution by $\mathrm{X}$-ray microanalysis (EMMA-4, AEI Scientific Apparatus Ltd). Previous studies of biological material using this technique have been reviewed by Robertson ${ }^{3}$, while methods of specimen preparation have been discussed by Andersen, ${ }^{4}$ and Beaman et al. ${ }^{5}$ 


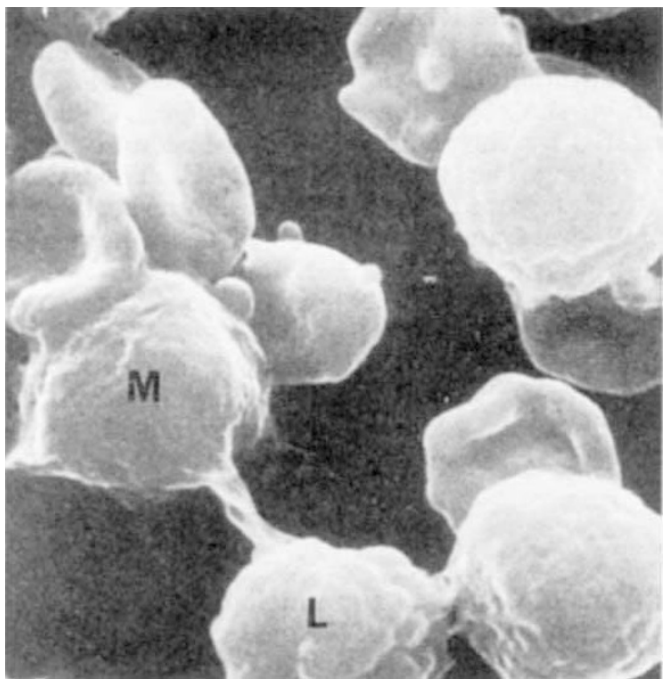

Fig. 1. Scanning electron micrograph of a typical intercellular process between a lymphocyte $(\mathrm{L})$ and a macrophage $(M)$. Some distorted red cells (due to incubation in the experimental conditions) and two other lymphocytes can also be seen. $(\times 2,250$. $)$

həve investigated the titanium and zinc content of blood cells.

Two $\mathrm{mg}$ of PPD was dialysed for $24 \mathrm{~h}$ against $0.15 \mathrm{M}$ phosphate buffer at $p H 7.2 ; 0.05 \mathrm{ml}$. of $0.1 \mathrm{~N}$ iodine in 0.15 per cent potassium iodide was then mixed with the PPD. $0.2 \mathrm{ml}$. of a 'Chloramine $T$ ' solution containing $500 \mu \mathrm{g}$ of the substance was added drop by drop to the mixture after PPD and iodine and the whole mixed for $10 \mathrm{~min} .1 .0 \mathrm{mg}$ of sodium metabisulphite was then added. The final mixture was drawn through two small quantities of 'Dowex' resin and sterilized by filtration through 'Millipore' filters (pore diameter $0.45 \mu \mathrm{m}$ ).

Rats were sensitized to tuberculin with Freund's complete adjuvant (CFA.Difco) in a dose of $0.5 \mathrm{ml}$. per animal. In each case, $0.1 \mathrm{ml}$. was injected into the superficial cervical lymph nodes, $0.1 \mathrm{ml}$. into each of the hind foot pads and $0.2 \mathrm{ml}$. into the back of the neck. Four weeks later, sensitized macrophages were harvested by peritoneal washing. $5 \times 10^{7}$ macrophages in $1.0 \mathrm{ml}$. were incubated for $30 \mathrm{~min}$ at $37^{\circ} \mathrm{C}$ with $1.0 \mu \mathrm{g}$ labelled PPD. The macrophages were then washed four times in medium 199 and incubated with the same number of sensitized rat lymph node cells suspended in medium 199 for $30 \mathrm{~min}$ at $37^{\circ} \mathrm{C}$.

The cell suspension was washed in isotonic phosphate buffer $p H 7.4$ and fixed for $1 \mathrm{~h}$ in isotonic 0.5 per cent glutaraldehyde in phosphate buffer. The fixed cells were washed in distilled water and the cell suspension transferred to an electron microscope grid coated with carbon. The cells were dried by the "critical point" method".

Intercellular processes were numerous and easily seen (by direct transmission imaging in EMMA-4) (Fig. 2). The processes varied between 2 and $30 \mu \mathrm{m}$ in length and between 0.3 and $4.0 \mu \mathrm{m}$ in diameter. Particular features of the specimen (Fig. 2) were chosen and the illumination focused onto these areas by exciting the "mini-lens" of the microscope to produce a probe of approximately $1000 \AA$ in diameter. The area for analysis was thus exactly located. X-rays emitted from the specimen were passed into the spectrometer and tuned for particular wavelengths by adjustment of the spectrometer geometry. $\mathrm{X}$-rays detected in the spectrometers were counted for a selected time at each area of the specimen. The count recorded was corrected by subtracting the background reading (with the spectrometer off the characteristic wavelength of iodine) from the peak reading (with the spectrometer tuned on the characteristic wavelength). As a check that the focused probe was always on the selected ares during analysis, the high phosphorus count entering a second spectrometer was observed-this also gave some indication of the mass thickness of the material.

With the probe over individual cells, corrected counts for iodine varied between 74 and 497 per 10 s. Every cell examined contained iodine, so it seemed reasonable to assume that, in a mixture containing equal numbers of macrophages and lymphocytes, iodine labelled PPD must have been transferred to the lymphocytes from macrophages. The cell marked $A$ in Fig. 2, over which a count of 74 was obtained, was used to check the spectrum of iodine. Fig. 3 shows that the true presence of iodine at that point was confirmed.

When the intercellular processes were examined, lower but still significant counts were obtained. For example, the corrected counts for iodine over a period of $10 \mathrm{~s}$ for the points along the process shown in Fig. 2 were as follows: $B, 91 ; C, 4 ; D, 11 ; E, 4 ; F, 95$. This characteristic of a higher count at the centre of a process than on each side of the centre was found on several occasions. With other processes, there was a steady fall in iodine counts with increasing distance from a cell, reaching a minimum at the centre of the process and rising again as the second cell was approached. In some instances, no iodine was detected in processes extending from cells which had not yet formed intercellular processes.

The error involved in any counts made on the spicimen was given statistically by the root mean square of the count. In particular, where low counts were detected, these values were checked for accuracy a number of times.

Other possible sources of error lay in the liberation of iodine from the iodo-protein. In these circumstances one would have expected to detect iodine lying outside cells or intercellular processes. This, in fact, never occurred. Iodo-proteins are known to be reasonably stable in the experimental conditions used. It was therefore concluded that any iodine count recorded originated in protein-bound iodine.

The potentiality of the EMMA-4 analytical electron microscope in detecting small quantities of elements at a cellular or intrasellular level has thus been demonstrated. The measurements in this instance were of a qualitative nature, but quantitative estimates are possible. The results suggest that iodine attached to PPD can pass along intercellular processes from cell to cell. The instru.

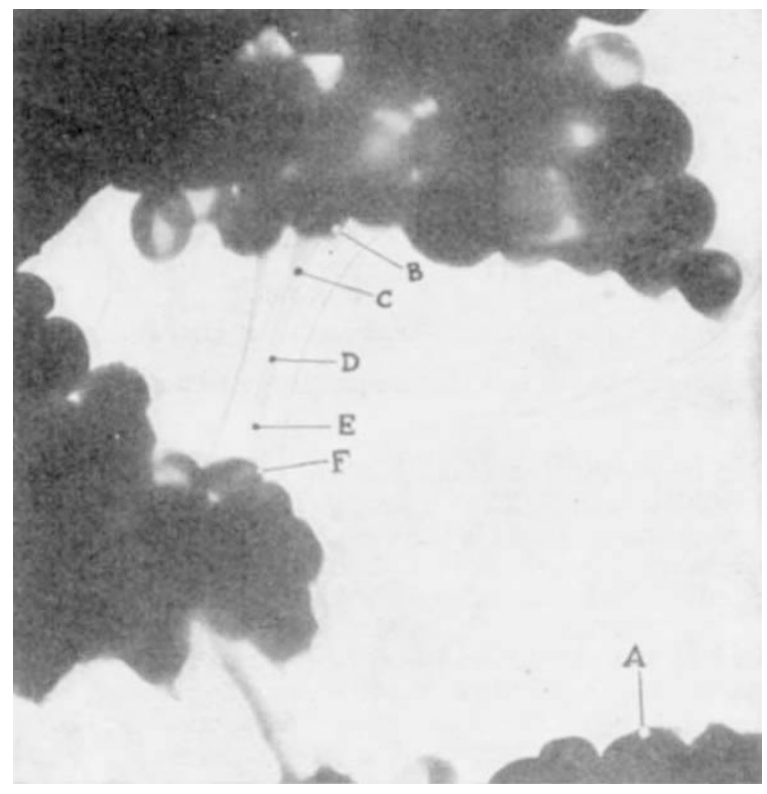

Fig. 2. Transmission electron micrograph (EMMA-4 at $100 \mathrm{kV}$ ) of intact groups of cells and intercellular processes. Letters indicato points of
analysis for iodine mentioned in the text. $(x 625$. 


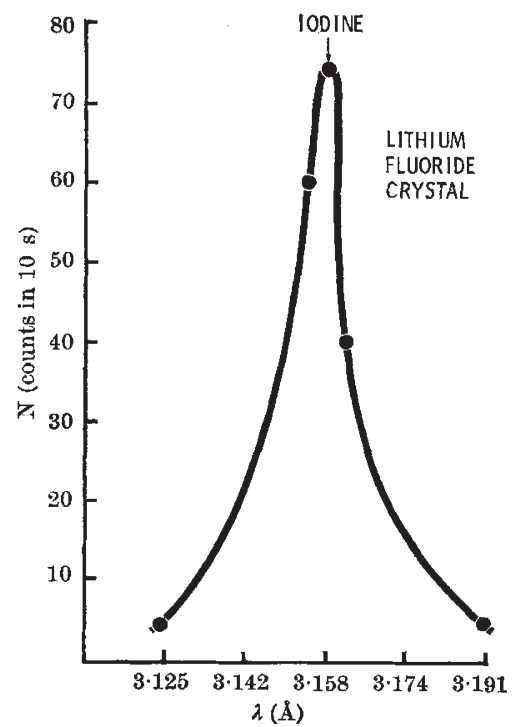

Fig. 3. Graph of counts at various wavelengths over point $A$ to confirm the true presence of iodine.

ment can detect sodium and heavier elements. Failure by other analysing techniques accurately to locate elements has previously made this kind of investigation impossible.

We thank AEI Scientific Apparatus Ltd for access to their analytical electron microscope and $\mathrm{Mr}$ John Chandle of their Consultant Laboratory for his help. Part of the work was supported by grants from the Discretionary Fund of the Governors of St Bartholomew's Hospital and the Wellcome Trust.

\section{J. A. Clarke}

Department of Anatomy,

ist Bartholomew's Hospital Medical College.

A. J. Salsbury

Department of Haematology,

D. A. WruxovghBy

Department of Experimental Pathology,

St Bartholomew's Hospital,

London.

Reecived April 7, 1970. 2 Clarke, J. A., Salsbury, A. J., and Willoughby, D. A., J. Path. Bact., 9B,
235 (1968).

${ }^{2}$ Clarke, J. A., Salsbury, A. J., and Willoughby, D. A., J. Path. Bact. (in

Robertson, A. J., Phys. Med. Biol., 13, 505 (1968).

Andersen, C. A., in Methods of Biochemical Analysis (edit. by Glick, D., 15, 147 (Interscience Publications, New York, 1967).

${ }^{5}$ Beaman, D. R., Nishiyama, R. H., and Penner, J. A., Blood, 84, 401 (1969).

- Anderson, T. F., Trans. NY Acad. Sci., 15, 130 (1951).

\section{Synergism between Thymocytes and Bone Marrow Cells in a Graft versus Host Reaction}

WE wish to describe synergism between two distinct populations of cells in the production of cellular immunity. Much work has concerned these cell types, particularly in relation to humoral immunity, and we shall first distinguish them. Both cell populations originate in the bone marrow. One type migrates to the thymus where it acquires special properties ${ }^{1,2}$; while there it is referred to as a thymocyte, but it may join the peripheral circulation and is then called a thymus-derived lymphocyte (TDL) ${ }^{3,4}$. The other type, the bone marrow-derived cell (BMDC), leaves the marrow to populate lymphoid organs or join the circulation, but does not pass through the thymus ${ }^{1-4}$.
In 1966 Claman, Chaperon and Triplett reported synergism between thymocytes and bone marrow cells in the production of humoral immunity ${ }^{5}$. Soon afterwards Davies et al. showed that while TDL did not produce antibody themselves, they greatly increased the ability of BMDC to do so ${ }^{6}$. Davies and co-workers, and Mitchell and Miller, have further defined the roles of these cells ${ }^{7,8}$. The question naturally arises whether a similar synergism exists in cellular immunity, which is known to be highly thymus dependent ${ }^{9,10}$. Simonsen's work on graft versus host (GVH) disease showed that the splenomegaly which occurs in Fl hosts is caused by cellular immunity, and provides a reliable measure for the $\mathrm{GVH}$ reaction ${ }^{11}$. We therefore tested the ability of thymocytes and BMDC to act synergistically in producing cellular immunity by using the GVH reaction as an assay in the manner of Simonsen.

Six week old, sublethally irradiated $(\mathrm{C} 3 \mathrm{H} / \mathrm{HeJ} \times \mathrm{DBA} /$ 2J) FI mice (CDF mice) were divided into several groups, each of which received intravenous injections of thymo. cytes, BMDC, spleen cells, or a combination of thymocytes and BMDC. A total of $3 \times 10^{7}$ cells per mouse was always given, half that number being contributed by each cell type in combinations. Experimental and control cells came from $\mathrm{C} 3 \mathrm{H} / \mathrm{HeJ}$ and $\mathrm{CDF}$ mice respectively. $\mathrm{C} 3 \mathrm{H}$ and DBA mice differ at the $H 2$ locus ( $H 2 k$ and $H 2 d)$, causing reliable GVH reactions ${ }^{11}$.

To find the time at which the GVH reaction was most prominent the CDF hosts were killed 6, 8, 10, 12 and 14 days after inoculation. Their spleens were removed, weighed, and spleen-to-body weight ratios determined. Each experiment was repeated at least once. Some 260 mice were studied, and results were statistically analysed with Student's $t$ test. Histological sections were taken of all spleens. Qualitative evidence of GVH disease was considered convincing when there was destruction of Malpighian follicles, infiltration of their regions by large pyroninophilic cells, and extensive proliferation of cells in the red pulp ${ }^{11}$.

The CDF hosts received 350 rad of total body irradiation $12 \mathrm{~h}$ before inoculation. This sublethal dose has been shown to enhance the susceptibility of adult mice to GVH disease by causing lymphoid depletion, which seems to make more room for donor cells to contact host
tissue $1 \mathbf{1 2 , 1 3}$.

To obtain spleen cells, fresh, adult spleens were cut into thirds, squeezed between glass slides, filtered, centrifuged, washed, and suspended in 'Medium 199' under sterile conditions. Viable cell counts were done with trypan blue. To obtain thymocytes, fresh weanling thymuses were cut in half and prepared like the spleen cells. For bone marrow-derived cells, six wee's old mice were thymectomized and lethally irradiated one week later with $850 \mathrm{rad}$, immediately following which they were given $5 \times 10^{6}$ bone marrow cells intravenously from syngeneic donors. Thirty days later their spleens were collected and cell suspensions were made as above. The combinations of thymocytes and BMDC were mixed in vitro and given at the same time as the other cells.

Parental spleen cells caused the most consistent and severe GVH reaction (Fig. 1). It was most prominent after 12 and 14 days, although it first appeared on the tenth day. None of the cell types caused any apparent GVH reaction before 10 days. $\mathrm{C} 3 \mathrm{H} / \mathrm{HeJ}$ thymocytes did not cause splenomegaly as compared with CDF thymo. cytes or radiation controls (Fig. 1); rather their spleens were significantly smaller than those controls $(P<0.001)$. $\mathrm{C} 3 \mathrm{H} / \mathrm{HeJ}$ BMDC produced no splenomegaly as compared with CDF spleen cells ( $P$ not significant) after 14 days (Fig. 1). In one experiment, however, they were larger than radiation controls after 10 days, but were slightly smaller after 14 days. At no time did they produce any histological evidence of GVH reaction, so that we conclude that BMDC alone did not cause GVH reaction in these doses. Parental thymocytes and BMDC combined in vitro 